\title{
EVALUATION OF KEY FACTOR OF DIGITAL ECONOMY IN EUROPEAN UNION
}

\author{
Ugnius Jakubelskas \\ Vilnius Gediminas Technical University, Vilnius, Lithuania, ugniusjakubelskas@gmail.com
}

Received 30 October 2021; accepted 30 November 2021

\begin{abstract}
Research purpose. This article presents insights on the concept and key factors of the digital economy based on a literature review. The article focuses on the identification of the factors of the digital economy and evaluation of their importance in terms of the European Union countries. The aim of the article is to determine the factors of the digital economy and evaluate their importance.
\end{abstract}

Design / Methodology / Approach. Panel regression analysis was used to evaluate which indicator of selected digital economy indicators is the most important. Panel regression was chosen to have an overall view of all European Union as one unit.

Findings. Digital technologies are radically changing the way society, business or the whole economy operates. The survey of this article reveals that the high-quality infrastructure of the internet plays an essential role in the digital economy. In order to create value and improve the ICT sector performance in the whole economy, high-quality infrastructure in terms of the internet is needed. Only fast and highstability connection ensures needed infrastructure and development in the digital economy. Business and government should invest in high-quality internet infrastructure to ensure the steady growth of the digital economy. To take full advantage of digital infrastructure and the digital economy, individuals should use it daily. Daily usage of the internet has a positive effect on the percentage for the ICT sector in GDP regardless of activities on the internet.

Originality / Value / Practical implications. Definition of the digital economy was suggested: the digital economy is considered to be all economic activities that include using or creating digital technologies to generate value-added of digital enablers and development of digital infrastructure, which is the key factor of the digital economy. High quality and available for everyone internet access is crucial for steady growth and the best performance of the digital economy. This study has several practical contributions. This survey may serve as a guide for understanding the concept and the factors of the digital economy for other researchers. We also propose a potential explanation why countries should invest in high technology infrastructure, and these results can help to create a new strategy for ICT sector expansion in different countries.

Keywords: digital economy; digital economy development; digital infrastructure; DESI, European Union.

JEL codes: M15, M21.

Citation: Jakubelskas, U. (2021). Evaluation of key factor of digital economy in European Union. Economics and Culture, 18(2), 41-50. https://doi.org/10.2478/jec-2021-0013

\section{Introduction}

The digital economy, being one of the six priorities announced by the European Commission for 2019-2024, confirms that society is living in the digital age and increasingly relies on digital technologies in daily activities (European Commission, 2019). The development of the digital economy has become one of the priorities in most countries, confirming that the advantages and 
opportunities of the digital economy are undoubted (Lyapuntsova et al., 2018). Expansion of digital-enabling infrastructure creates new areas of scientific research and innovations, services, economic growth, and improvement in the quality of life of the society.

Even though the digital economy is emerging as a catalyst for globalisation, it is also a key driver of growth and development, boosting competitiveness across all sectors (Mukhtorovna, 2021). The digital economy ensures better communication, information exchange, efficiency and enables collaboration which is needed in order to cover all growing needs of society (Mahmudov Baxriddin Jurayevich and Mullabayev Baxtiyarjon Bulturbayevich, 2020). A better understanding of the digital economy can help businesses improve their production capacity; however, the most important feature of the digital economy is an expansion to the new and biggest market: the internet. In order to succeed in the global market, principles should be examined (Danilin, 2019).

Based on that, it is essential to understand the concept of the digital economy and its main factors. The concept, development, and perspectives of the digital economy have been examined since 1996 (Tapscott, 1996); however, a unified concept and factors of the digital economy have not been developed yet. That encourages to look for new perspectives and aligns with the aim of this article: to identify the factors of the digital economy and evaluate their importance in terms of the European Union countries. In order to reach the aim of the paper, the concept of the digital economy was highlighted, and the factors of digital economy development were examined. A suitable methodology for assessing the factors of the digital economy in the EU was chosen, and an evaluation of the factors of the digital economy in the EU was performed.

Like every study, the present one has several limitations. The data of digital infrastructure and usage was used in this article as factors of the digital economy, but due to missing data, several countries were excluded from the research. They are as follows: Cyprus, Denmark, Ireland, Luxembourg, Netherlands, Portugal, Spain, Sweden. Data used for the year 2015-2019 (2019 data of the percentage of the ICT sector in GDP were not published and were predicted using moving average. There might be some deviations from the actual data of this indicator in 2019).

This paper is organised as follows: the theoretical background section gives a comprehensive literature review; the methodology part describes the methods used in the research and selected indicators. Empirical findings illustrate the empirical data used in the research and numerical expressions, the results of the survey and possible causes, while the conclusion gives some concluding remarks.

\section{Theoretical Background}

According to World Economic Forum (2016), the digital economy affects all aspects of society, including the economic landscape, the way of collaboration and communication between people, the abilities needed to get a decent job, and even how political decisions are made. Although the digital economy is a part of our daily life, the concept is not clear yet. It is a lack of a globally agreed definition of the digital economy and unified evaluation system. The goal of this section is to describe the concept and development of the digital economy and identify the factors that reveal the development of the digital economy.

The term digital economy was first described by Tapscott in 1996 as a tool of using technologies and networking of human beings to create wealth and enhance social development through a combination of creativity, intelligence, and knowledge for breakthroughs (Tapscott, 1996). Since there is no internationally agreed definition of the digital economy, it is crucial to compare definitions from different sources to get a better understanding of what the digital economy is.

According to Chen (2020), narrowly, the digital economy can be defined as economic activities in the information and communication technologies (ICT) sector, including the internet, IT services, telecommunication, etc. The broad definition covers the combined value of information and communication technologies (ICT) production and digital inputs to the rest of the economy. Most importantly, if we would consider that the digital economy covers all 
economic activities that use or are facilitated by digitised data, we could say that the digital economy is a great part of nowadays economy.

The digital economy, as reported by Skilton (2015), is a part of the digital ecosystem which is an interaction of information technologies and business to create new consumers, determine better business results, etc. The digital economy is considered as virtual resources and digital services to create added value for both individuals and businesses or countries. According to the World Bank Group (2016), the digital economy is doing business and using digital technologies across all sectors, including education, manufacturing, healthcare, transportation, agriculture, entertainment, etc., and cannot be limited by e-commerce or e-business. One of the main advantages of the digital-based business is the low marginal cost to enter the business; however, that also leads to higher competition (Chohan, 2020). The digital economy is an accelerator of global economic development that increases the productivity of existing industries and opens opportunities for new markets and industries, providing sustainable growth. At the same time, the digital economy connects different communities, industries, ideas, or products and allows different parts to collaborate and raise the value chain.

The digital economy is a result of the widespread implementation of ICT into the economy and is considered through the creation, processing, and use of information and knowledge presented in digital form. Digitalisation covers most spheres of the economy nowadays and brings digital technologies and knowledge as a base for new digital skills, opportunities, and value for business or society (Puzina et al., 2021).

Kim et al. (2014) stated that the digital economy is a step toward a knowledge-based society. The digital economy grows faster and faster and overtakes the traditional industrial economy. The key factor of the digital economy is the development of information and communication technologies (ICT) and innovations creating new economic growth structures in all aspects of life. Besides the digitalisation of core economic activities as production, distribution, and consumption of goods and services, one of the essential properties of the digital economy is its inclusion of knowledge and information in main production factors. Digitalisation is a part of almost all economic activities, and it is constantly expanding (Szeles \& Simionescu, 2020). Recent transformation to digitalisation in every part of the economy created new opportunities and showed that it is possible to exchange data as a new good in the market. As stated by Shi et al. (2021), the digital economy is an essential driving force of global economic and social development. Digital technology as an enabler of the digital economy ensures productivity improvement, which is reflected in the progress of use-value, efficiency, quality, and cost.

Based on all definitions, the digital economy is considered as all economic activities that include using or creating digital technologies to generate value-added of digital enablers and development of digital infrastructure.

Barefoot et al. (2018) state that the digital economy starts with the digital-enabling infrastructure, which is crucial for a computer network to exist and operate. The digital economy includes all digital transactions made using that infrastructure, and the result is all the content that digital economy users create and access.

As stated by Tian and Liu (2021), the digital economy covers all economic activities in which the key factors are digital knowledge and information, modern networks, ICT. All these factors improve efficiency and structural optimisation. The digital economy as a priority of countries' development strategies becomes the main driving force of the future economy.

According to the European Commission (2014), the digital economy cannot be described as a separate part of the mainstream economy. European Commission declares that the main factors of the digital economy are mobility, network effects, and the use of data. It is stated that the digital economy sometimes can be called the internet economy. As reported by OECD (2018), the digital economy relies on or is enhanced by the use of digital inputs that includes digital technologies, infrastructure, services and data. It covers all producers and consumers, including the government. Izmaylov et al. (2018) also stated that the digital economy could be described by three main parts: infrastructure, including development and support of both hardware and software, telecommunication systems and networks, electronic business, including automation 
of business processes and use of technologies; e-commerce business. The main factors and driving forces of a fully effective digital economy are human resources and intellectual capital.

To sum up, all of the mentioned factors of the digital economy have some touchpoints. The most important factor of the digital economy is infrastructure. The use of that infrastructure creates digital goods and services that can be provided or used by private individuals, businesses, or the public sector. As stated by Bukht and Heeks (2018), the internet was the foundation of the digital economy, and it is still one of the main factors of success in the digital economy. The development of the internet made massive progress in the digital economy introducing new technologies such as the internet of things or 5G, but the internet itself remains the main factor of the digital economy. Since the internet plays a crucial role in the digital economy, two different indicators were included in our evaluation system that covers overall internet infrastructure (accessibility for the households) and accessibility of more advanced internet connection that is needed to take full advantage of the digital economy. High technology internet infrastructure allows all households, businesses, or governments to benefit from an enhanced and more efficient broadband internet connection. Companies are enabled to increase their capacities; households can enjoy a better online experience and use multiple devices or services simultaneously (Hasbi, 2017).

Another common factor of the digital economy mentioned in most of the definitions was that the digital economy cannot be limited by e-commerce and covers lots of different services online. Only the digital infrastructure is not enough for the successful performance of the digital economy. It is essential that society has at least basic digital skills and is able to use digital services such as internet banking, e-government, social networks, e-health and others. Taking advantage of digital infrastructure equals using different digital services as often as possible. This also has advantages as time-saving, operational coast optimisation tools and acts as the key to inclusive economic and social development in the digital economy (The Monetary Authority of Singapore, 2021). Since the definition of the digital economy varies, it can be complicated to select one indicator that covers the overall performance of the digital economy. However, often as mentioned before, the digital economy is based on the ICT sector (Chen, 2020; Puzina et al., 2021; Tian \& Liu, 2021), and its added value on GDP can be considered as the overall performance of the digital economy in the whole economy (Herbert \& Loudon, 2020)

From a methodological view, there are several different studies focused on the evaluation of the digital economy, including the Digital Economy and Society Index (DESI) proposed by the European Commission. The structure of the DESI index is shown in Table 1.

Table 1. Dimensions of Digital Economy and Society Index (Source: Bánhidi et al., 2020; Česnauskè, 2019; European Commission, 2021; Kontolaimou \& Skintzi, 2018)

\begin{tabular}{|c|c|}
\hline Connectivity & $\begin{array}{c}\text { Measures the deployment of broadband } \\
\text { infrastructure and its quality }\end{array}$ \\
\hline Human capital & $\begin{array}{c}\text { Measures the basic and advanced digital skills } \\
\text { needed to participate and take advantage of the } \\
\text { digital economy }\end{array}$ \\
\hline Use of internet & $\begin{array}{c}\text { Measures variety of online activities performed } \\
\text { by citizens }\end{array}$ \\
\hline Integration of digital technologies & $\begin{array}{c}\text { Measures the digitisation of businesses. E- } \\
\text { commerce and other digital solutions for business. }\end{array}$ \\
\hline Digital public services & $\begin{array}{c}\text { Measures the digitisation of public services, } \\
\text { increasing efficiency of public administration. } \\
\text { Accessibility of digital public services focusing } \\
\text { on eGovernment or eHealth }\end{array}$ \\
\hline
\end{tabular}

In overall DESI calculation, each dimension has its weight: connectivity - $25 \%$, human capital $25 \%$, use of the internet $-15 \%$, integration of digital technologies $-20 \%$, digital public services 
- $15 \%$. Based on this distribution, digital infrastructure, and its quality, as well as basic and advanced digital skills needed for the digital economy, are considered as the most relevant dimensions.

In the technology-oriented world, individuals are more connected than ever before. The considerable expansion in connectivity across the entire society proves that infrastructure and the development of broadband connection are crucial for the digital economy. It is likely that we will go even further with the growth of digital tools and communication (Stoica \& Bogoslov, 2017).

According to Folea (2018), the EU should consider improving its strategy for digital skills and align regulations to improve. It is urgent to significantly increase the number of people with basic and advanced digital skills to take advantage of the digital economy. Kontolaimou \& Skintzi (2018) agree that human capital plays a critical role in the digital economy and affects its performance. The digital divide is a critical issue, whether it concerns inequalities between countries but also within different social groups. The digital gap should be minimised to achieve inclusive growth of the digital economy.

The DESI index describes the progress of EU countries in the development of the digital economy and society and allows the justification of areas where such changes should be the priority (Stavytskyy et al., 2019). According to Stoica \& Bogoslov (2017) DESI index is connected to the policy of the digital economy in European Union and shows the overall view of the digital economy in the whole Europe. European Commission's goal to create the single digital market in Europe confirms that changes should be implemented in the whole union, and the gap between leading and following countries in terms of the digital economy should be minimised. As stated by Bánhidi et al. (2020), the main advantage of the DESI index is that it is measured all across Europe and enables comparison between countries and provides a picture of the digital ecosystem and overall performance of the digital economy in the EU.

\section{Methodology}

First, in order to have a further study of the development of the digital economy in Europe, the digital economy indicator evaluation system was constructed by selecting relevant digital economy indicators. To evaluate digital economy development in Europe panel regression model was used.

The Hausman test was performed to evaluate which model (fixed effect or random effect) applies to the data. The null hypothesis is that the preferred model is random effects, and the alternate hypothesis is that the model is fixed effects. In the current case, the p-value of the Hausman test was 0,9903 , which means that the alternative hypothesis should be rejected, and the model is considered as a random effect.

Moreover, the data was checked for cointegration using the Kao cointegration test. According to the Kao Augmented Dickey-Fuller test, the p-value is equal to 0.0049 , which means that all the panels are cointegrated.

Regression analysis was performed using panel data. The p-value provides information about the probability that the data would be inconsistent. It is generally assumed that a p-value $\leq 0.05$ implies that results are significant (Bermudez-Edo et al., 2018). The coefficient of determination (or $\mathrm{r}$ squared) gives information about the proportion of variation in the dependent variable, which might be considered as being associated with the variation in the independent variable (Bolboaca \& Jäntschi, 2006).

Panel data contain information on temporal and spatial dimensions. The temporal dimension is when repeated measurements are made, such as month or year. The spatial dimension is the unit of observations such as firms or countries. One of the advantages of using panel data is to increase the number of observations for the analysis and minimise the standard errors probability (Xu et al., 2007).

The general multiple regression model of panel data in this article can be expressed as follows: 
where

$y$ is the dependent variable percentage of the ICT sector on GDP

$\beta_{i t}$ is the coefficient of each explanatory variable

$u_{i t}$ is intercept

Il Households - level of internet access

I2 Households - type of connection to the internet

U1 Individuals - internet use

U2 Individuals - frequency of internet use

Al Individuals - internet activities: Internet banking

A2 Internet purchases by individuals

A3 E-government activities of individuals via websites: submitting completed

A4 E-government activities of individuals via websites: interaction with public authorities

The data required to perform the study are collected from Eurostat. All the data are public and available on the Eurostat website. Due to the lack of statistical data, some values were calculated using moving average as a widely known technical indicator used to predict the future data in time series analysis.

A set of 9 variables was extracted that measure the digital infrastructure and usage of that infrastructure for different digital services or online activities. Among them, two variables are related to digital infrastructure; two indicators reveal overall usage of the internet, other four are related to individuals and usage of different activities using the internet, including e-commerce and digital public services.

Two indicators that are related to digital infrastructure (I1 and I2) for the year 2015-2019 are the following:

- I1 Households - level of internet access - indicator is given as a percentage of households that has an internet connection.

- I2 Households - type of connection to the internet - indicator represents the percentage of households that has a broadband internet connection.

Two indicators that are related to the overall usage of the internet (U1 and U2) for the year 2015-2019 are the following:

- U1 Individuals - internet use - a percentage of all the individuals that have accessed the internet in the last 12 months.

- U2 Individuals - frequency of internet use - indicator represents the percentage of individuals that use the internet daily.

Four indicators that are related to the usage of different online services (A1 and A4) for the year 2015-2019 are the following:

- A1 Individuals - internet activities: Internet banking - the percentage of all individuals that have used the internet for internet banking.

- A2 Internet purchases by individuals - the percentage of all individuals that have made an online purchase in the last three months.

- A3 E-government activities of individuals via websites: submitting completed forms the percentage of individuals that have submitted completed forms for government institutions in the last 12 months.

- A4 E-government activities of individuals via websites: interaction with public authorities - the percentage of individuals that have been interacting with public authorities online in the last 12 months.

The final indicator is related to the overall performance of the ICT sector as the key sector of the digital economy in the overall economy. The indicator for the year 2015-2018 is the following: 
- Percentage of the ICT sector on GDP - value added at factor cost in the ICT sector as a percentage of total value added at factor cost. The indicator includes both ICT manufacturing and ICT services. Value-added at factor cost is defined as Gross value added (at basic prices) minus other taxes, minus other subsidies on production. For the year 2019, since the data is not published yet moving average method was applied, and missing values were generated.

\section{Results}

In this section, the results of panel regression analysis are presented. Multiple panel regression analysis was performed, and results are given in Table 2 .

Table 2. Percentage of the ICT sector in GDP, Households - level of internet access and Individuals - internet use; frequency of internet use; internet activities: internet banking multiple panel regression results (Source: made by the author)

\begin{tabular}{|c|r|r|r|r|}
\hline & & Coefficients & $\begin{array}{r}\text { Coefficient of } \\
\text { determination }\end{array}$ & p-value \\
\cline { 1 - 3 } $\begin{array}{c}\text { Households - level of internet } \\
\text { access }\end{array}$ & I1 & 0,0540 & & \\
\cline { 1 - 3 } Individuals - internet use & $\mathrm{U} 1$ & $-0,0526$ & \multirow{2}{*}{0,30486} & 0,000029 \\
\cline { 1 - 3 } $\begin{array}{c}\text { Individuals - frequency of } \\
\text { internet use }\end{array}$ & $\mathrm{U} 2$ & 0,0374 & & \\
\cline { 1 - 3 } activities: Internet banking & $\mathrm{A} 1$ & $-0,0256$ & & \\
\hline
\end{tabular}

As shown in Table 2, the results are statistically significant based on the p-value. The coefficient of determination is 0,30486 . Based on provided coefficients of variables, the panel regression equation of percentage of the ICT sector in GDP and four independent variables: Households - level of internet access, Individuals - internet use, Individuals - frequency of internet use and Individuals - internet activities: internet banking would be:

$$
y=0,0540 \times I 1-0,0526 \times U 1+0,0374 \times U 2-0,0256 \times A 1
$$

The given value of the coefficient of determination shows that $30,486 \%$ of the data fit the regression model. The model is considered statistically significant. In order to predict values given regression equation can be used. The coefficient of I1 indicates that for every additional percentage of Households - level of internet access, we can expect the percentage of the ICT sector in GDP to increase by an average of 0,0540 while other variable does not change. The coefficient of U1 indicates that for every additional percentage of Individuals - internet use, we can expect the percentage of the ICT sector in GDP to decrease by an average of 0,0526 while other variable does not change. The coefficient of $\mathrm{U} 2$ indicates that for every additional percentage of Individuals - frequency of internet use, we can expect the percentage of the ICT sector in GDP to increase by an average of 0,0374 while other variable does not change. The coefficient of A1 indicates that for every additional percentage of Individuals - internet 
activities: Internet banking, we can expect the percentage of the ICT sector in GDP to decrease by an average of 0,0526 while other variable does not change.

Variables' correlation coefficients given in Table 2 reveal some interesting findings. It demonstrates the fact that to create value and improve the ICT sector performance in the whole economy, high-quality infrastructure in terms of the internet is necessary. Only fast and highstability connection ensures needed infrastructure and development in the digital economy. In order to achieve a better result in the ICT sector, countries or businesses should invest in modern new internet infrastructure technologies such as 5G or others. Another interesting finding is that to take full advantage of that infrastructure; individuals should use it daily. As shown in Table 2, the daily usage of the internet has a positive effect on the percentage of the ICT sector in GDP regardless of activities on the internet. Only increasing constant internet usage as a whole with all different services and activities can increase the percentage of the ICT sector in GDP. Also, individuals who use the internet daily likely use more services. Individuals should use as many digital services as possible to create additional value for the ICT sector.

It is important to mention that results are considered statistically significant based on p-value and determination coefficient. Given the value of the coefficient of determination shows that $30,486 \%$ of the data fit the multiple panel regression model. It is essential to understand that internet infrastructure and usage are one of the key indicators of ICT or digital economy, but it is not enough for a complete analysis to create an accurate model. In order to have more representative data, more variables should be included to increase the accuracy of the regression analysis. As shown in the panel regression equation, the expansion of internet access for households has a positive effect on the percentage of the ICT sector in GDP. As for the usage of the internet, it is important to mention that the internet should be used on a daily basis to improve the results of the digital economy since individuals that access the internet only once in 12 months cannot be considered as playing an active role in the digital economy and do not create an added value to the performance of the digital economy.

\section{Conclusions}

In this paper, a comprehensive literature review of different definitions of the digital economy was performed. The definition of the digital economy developed over time, starting with a considerable expansion of the internet, and can no longer be limited to e-commerce. By creating new markets, services and goods, the digital economy became the priority of most countries. In this paper, the digital economy is considered as all economic activities that include using or creating digital technologies to generate additional value and development of digital technologies. The key factor of the digital economy - infrastructure and use of digital services became an object for the empirical study of this paper. The most important variable, as the study showed, is Households - level of internet access. The level of internet access refers to the infrastructure needed for the digital economy to exist. In order to take advantage of the digital economy, high-quality infrastructure is needed for the steady growth of the digital economy. It also confirms the insights stated in the theoretical part of this article that infrastructure is the most important feature of the digital economy.

This study has several practical contributions. This survey may serve as a guide for understanding the concept and the factors of the digital economy for other researchers. We also propose a potential explanation why countries should invest in high technology infrastructure, and these results can help to create a new strategy for ICT sector expansion in different countries.

Limitations of this study present new opportunities for future research. For future research, the study can be expanded to more countries, also can be performed again after new data is published to have precious results. For future research, more indicators can be included based on available data to have a wider view of the overall performance of the digital economy.

\section{References}

Bánhidi, Z., Dobos, I., \& Nemeslaki, A. (2020). What the overall Digital Economy and Society Index 
reveals: A statistical analysis of the DESI EU28 dimensions. Regional Statistics, 10(2), 46-62. https://doi.org/10.15196/RS100209

Barefoot, K., Custis, D., Jolliff, W., Nicholson, J., \& Omohundro, R. (2018). Defining and Measuring the Digital Economy. https://www.bea.gov/system/files/papers/WP2018-4.pdf

Bermudez-Edo, M., Barnaghi, P., \& Moessner, K. (2018). Analysing real world data streams with spatiotemporal correlations: Entropy vs. Pearson correlation. Automation in Construction, 88, 87-100. https://doi.org/10.1016/j.autcon.2017.12.036

Bolboaca, S.-D., \& Jäntschi, L. (2006). Pearson versus Spearman, Kendall's Tau Correlation Analysis on Structure-Activity Relationships of Biologic Active Compounds. Leonardo Journal of Sciences, 9.

Bukht, R., \& Heeks, R. (2018). Defining, Conceptualising and Measuring the Digital Economy. International Organisations Research Journal, 13(2), 143-172. https://doi.org/10.17323/1996-78452018-02-07

Česnauskè, J. (2019). Digital Economy and Society: Baltic States in the EU Context. Economics and Culture, 16(1), 80-90. https://doi.org/10.2478/jec-2019-0009

Chen, Y. (2020). Improving market performance in the digital economy. China Economic Review, 62, 101482. https://doi.org/10.1016/j.chieco.2020.101482

Chohan, U. W. (2020). Some Precepts of the Digital Economy. SSRN Electronic Journal. https://doi.org/10.2139/ssrn.3512353

Danilin, I. V. (2019). Development of the Digital Economy in the USA and China: Factors and Trends. Outlines of Global Transformations: Politics, Economics, Law, 12(6), 246-267. https://doi.org/10.23932/2542-0240-2019-12-6-12

European Commission. (2014). Commission Expert Group on Taxation of the Digital Economy.

European Commission. (2019). A Europe fit for the digital age. https://ec.europa.eu/info/strategy/priorities-2019-2024/europe-fit-digital-age_en

European Commission. (2021). International Digital Economy and Society Index 2020. 61. https://doi.org/10.2759/757411

Folea, V. (2018). European public policies in the area of the digital economy and society: country performance analysis. CBU International Conference Proceedings, 6, 120-128. https://doi.org/10.12955/cbup.v6.1143

Hasbi, M. (2017). Impact of Very High-Speed Broadband on Local Economic Growth: Empirical Evidence. 14th Asia-Pacific Regional Conference of the International Telecommunications Society (ITS). http://hdl.handle.net/10419/168484

Herbert, G., \& Loudon, L. (2020). The Size and Growth Potential of the Digital Economy in ODA-eligible Countries. https://doi.org/10.19088/K4D.2021.016

Izmaylov, Y., Yegorova, I., Maksymova, I., \& Znotina, D. (2018). b. Scientific Journal of Polonia University, 27(2), 52-60. https://doi.org/10.23856/2706

Kim, T.-Y., Kim, E., Park, J., \& Hwang, J. (2014). The Faster-Accelerating Digital Economy. In Economic Growth (pp. 163-191). Springer Berlin Heidelberg. https://doi.org/10.1007/978-3-642-408267_5

Kontolaimou, A., \& Skintzi, G. (2018). Digitisation patterns of the Greek economy and society. Greek Economic Outlook, 37, 41-48. https://www.researchgate.net/publication/328981700

Lyapuntsova, E., Belozerova, Y., Drozdova, I., Afanas'ev, G., \& Okunkova, E. (2018). Entrepreneurial Risks in the Realities of the Digital Economy. MATEC Web of Conferences, 251, 06032. https://doi.org/10.1051/matecconf/201825106032

Mahmudov Baxriddin Jurayevich, \& Mullabayev Baxtiyarjon Bulturbayevich. (2020). The impact of the digital economy on economic growth. International Journal on Integrated Education, 3(6), 16-18. https://doi.org/10.31149/ijie.v3i6.394

Mukhtorovna, N. D. (2021). Importance of foreign investments in the development of the digital economy. ResearchJet Journal of Analysis and Inventions, 2(4), 219-224. https://reserchjet.academiascience.org/index.php/rjai/article/view/89/79

OECD. (2018). Toolkit for Measuring the Digital Economy, G20 Digital Economy Task Force. 
https://www.oecd.org/g20/summits/buenos-aires/G20-Toolkit-for-measuring-digital-economy.pdf

Puzina, N., Reutova, I., Leshenko, N., Khobotova, S., \& Katunina, N. (2021). The Digital Economy: Approaches to the Definition and the Regional Dimension. SHS Web of Conferences, 93, 05016. https://doi.org/10.1051/shsconf/20219305016

Shi, Y., Yu, S., \& Zhang, P. (2021). Expected Economic Theory and Its Model Construction. Procedia Computer Science, 187, 524-529. https://doi.org/10.1016/j.procs.2021.04.094

Skilton, M. (2015). Building the Digital Enterprise. Palgrave Macmillan UK. https://doi.org/10.1057/9781137477729

Stavytskyy, A., Kharlamova, G., \& Stoica, E. A. (2019). The Analysis of the Digital Economy and Society Index in the EU. Baltic Journal of European Studies, 9(3), 245-261. https://doi.org/10.1515/bjes2019-0032

Stoica, E. A., \& Bogoslov, I. A. (2017). A Comprehensive Analysis Regarding DESI Country Progress for Romania Relative to the European Average Trend. Balkan Region Conference on Engineering and Business Education, 2(1), 258-266. https://doi.org/10.1515/cplbu-2017-0034

Szeles, M. R., \& Simionescu, M. (2020). Regional Patterns and Drivers of the EU Digital Economy. Social Indicators Research, 150(1), 95-119. https://doi.org/10.1007/s11205-020-02287-X

Tapscott, D. (1996). The Digital Economy: Promise and Peril in the Age of Networked Intelligence. 342. https://doi.org/10.5465/ame.1996.19198671

The Monetary Authority of Singapore. (2021). Foundational digital infrastructures for inclusive digital economies.

Tian, J., \& Liu, Y. (2021). Research on Total Factor Productivity Measurement and Influencing Factors of Digital Economy Enterprises. Procedia Computer Science, 187, 390-395. https://doi.org/10.1016/j.procs.2021.04.077

Worl Economic Forum. (2016). The digital economy: what is it and how will it transform our lives? https://www.weforum.org/agenda/2016/11/the-digital-economy-what-is-it-and-how-will-it-transform-ourlives/

World Bank Group. (2016). Digital Economy Concept, Trends and Visions: Towards a Future-Proof Strategy. https://pubdocs.worldbank.org/en/513361482271099284/Digital-Economy-Russia-Discussionpaper-2016-12-20-eng.pdf

Xu, H., Hwan Lee, S., \& Ho Eom, T. (2007). Introduction to Panel Data Analysis. https://doi.org/10.1201/9781420013276.ch32 